\title{
Allometric growth and sperm competition in fishes
}

\author{
J. A. Stoltz*, B. D. NefF*† and J. D. Olden \\ *Department of Biology, University of Western Ontario, London, Ontario N6A 5B7, \\ Canada and \$Center for Limnology, University of Wisconsin, 680 N. Park Street, \\ Madison, Wisconsin, 53706, U.S.A.
}

(Received 14 September 2004, Accepted 18 February 2005)

\begin{abstract}
The allometric relationship between body mass and gonad mass in males of 23 fish species from 11 families was examined. There was no evidence of a single allometry for all fishes. A cross species analysis suggested a scaling coefficient of $1 \cdot 04$, which was significantly different from a previous study that reported a scaling coefficient of 0.904 . A within species analysis generated scaling coefficients from 0.68 to $3 \cdot 90$. Furthermore, for those species characterized by alternative mating tactics, there was no correlation between the scaling coefficients of bourgeois-type males and parasitic-type males. These results are discussed in the context of the gonado-somatic index and its use in testing sperm competition theory.

(C) 2005 The Fisheries Society of the British Isles
\end{abstract}

Key words: allometry; gonad; sperm competition; testes.

\section{INTRODUCTION}

Sperm competition is a powerful, yet often cryptic, form of sexual selection that occurs in a range of animals (Birkhead \& Møller, 1991; Møller \& Birkhead, 1998; Simmons, 2001). Defined as the competition between the sperm of two or more males for the fertilization of a given set of eggs, sperm competition has led to a wide range of behavioural, morphological and physiological adaptations that enhance the success of a male's sperm relative to that of a rival (Parker, 1970; Smith, 1984). One male morphological trait that appears to show consistent adaptation to the degree of sperm competition is gonad size, with a positive relationship between gonad size and the level of sperm competition having been documented in, for example, primates (Harcourt et al., 1981), birds (Møller \& Briskie, 1995), frogs (Jennions \& Passmore, 1993), butterflies (Gage, 1994) and fishes (Stockley et al., 1997).

Theory suggests that an increase in the level of sperm competition should lead to an increase in the relative investment into sperm production (Parker, 1990). This theory has received widespread support from studies of fishes, where relative investment into sperm production is commonly measured during the breeding season by the gonado-somatic index $\left(I_{\mathrm{G}}\right)$ (Taborsky, 1998). The $I_{\mathrm{G}}$ is calculated by dividing gonad mass by total body mass and can be expressed as a

†Author to whom correspondence should be addressed. Tel.: +1 519850 2532; fax: +1 519661 3935; email: bneff@uwo.ca 
percentage. The $I_{\mathrm{G}}$ is an attractive approach to measuring the relative investment into sperm production because it is simple to calculate and appears to control for differences in body size and hence an individual's overall energy budget. Using $I_{\mathrm{G}}$ to test Parker's (1990) theory has been criticized recently by Tomkins \& Simmons (2002) who correctly pointed out that the simple $I_{\mathrm{G}}$ ratio will only control for differences in body size if there is an isometric relationship between gonad mass and body mass (DeVlaming et al., 1982). Such an isometric relationship would exist only if gonad mass scales linearly to body mass.

Isometric relationships appear to be rare in nature (Gould, 1966). Specifically for fishes, Stockley et al. (1997) found a non-linear relationship between mean gonad mass and mean body mass for 19 teleost species. By plotting $\log _{10}$ (gonad mass) as their $y$-variable and $\log _{10}$ (body mass) as their $x$-variable, and using the slope from a least-squares linear regression, the authors were able to calculate the scaling exponent from the standard allometric equation $y=\beta x^{\alpha}$ (Brody, 1945). A linear relationship exists when $\alpha=1$. For Stockley et al.'s (1997) data set the scaling exponent was originally calculated as $0 \cdot 75$, indicating that there was a negative allometric relationship between gonad and body masses. The slope (i.e. functional relationship) calculated from a least-squares linear regression (model I), however, is biased when there is error in both the $x$ and $y$ variables. Instead, the slope of the major axis is recommended and it can be calculated from the slope from the least-squares regression by dividing the slope by the correlation coefficient $r$ (Zar, 1968; Ricker, 1973; Ebert \& Russell, 1994). For Stockley et al.'s (1997) data the correlation coefficient was 0.83 and therefore the slope of the major axis is $0.904(=0 \cdot 75 / 0 \cdot 83)$. This slope implies that larger individuals have relatively smaller gonads than smaller individuals; that is, larger individuals have a lower $I_{\mathrm{G}}$ than smaller individuals. If there is in fact a negative allometric relationship between gonad and body masses in fishes, then comparing the $I_{\mathrm{G}}$ of individuals that differ in the level of sperm competition can be misleading. For example, if larger fish (either within species or across species) typically experience a lower level of sperm competition, then these individuals may appear to invest less in sperm production because they have lower $I_{\mathrm{G}}$ than smaller fish.

Species that are characterized by two male morphs that utilize alternative mating tactics may be particularly prone to erroneous interpretation of $I_{\mathrm{G}}$ values. These alternative mating tactics have been generally termed 'bourgeois' and 'parasitic' (Taborsky, 1998). Bourgeois males typically monopolize resources, such as spawning sites, food and shelter or females directly to prevent rival males from gaining access to eggs. Conversely, parasitic males attempt to exploit the reproductive effort of bourgeois males and often the sperm of bourgeois and parasitic males compete to fertilize a female's eggs. Bourgeois males usually experience a lower level of sperm competition than parasitic males. For example, in the bluegill Lepomis macrochirus Rafinesque, Neff et al. (2003) found that bourgeois males experienced sperm competition $c .20 \%$ of the time, the remaining $80 \%$ of the time the bourgeois male was alone with the female, while parasitic males experienced sperm competition $100 \%$ of the time. Furthermore, they found that bourgeois males had $I_{\mathrm{G}}$ values that were about one third those of parasitic males. Thus, these data appear to provide support for Parker's (1990) theory although Neat (2001) provides an exception. Bourgeois 
males in bluegill, however, are significantly larger than parasitic males, thereby potentially confounding Neff et al.'s (2003) comparison of $I_{\mathrm{G}}$ values.

The purpose of the present study was to test whether or not an allometric relationship exists between gonad and body masses in fishes. Specifically, the scaling exponent was calculated using data from 23 different species in 11 families of teleosts, and compared between species means, individuals within species, and individuals within mating tactics (bourgeois or parasitic). The aims of this study were to help direct the use of $I_{\mathrm{G}}$ in future studies of sperm competition in fishes.

\section{MATERIALS AND METHODS}

\section{DATA COLLECTION}

In December of 2002, the Web-of-Science (http://isiknowledge.com/) was used to search for papers on 'fish' and 'gonads or testes.' From these papers the senior authors were contacted and data requested on individual gonad mass, body mass and reproductive status. The analysis was limited to data from mature fishes that were collected during the reproductive season.

\section{ALLOMETRY ACROSS SPECIES}

For each species, gonad and body masses were averaged across individuals. For each species that had alternative male morphs, all males were initially pooled together. The species averages were then subjected to a $\log _{10}$ transformation and a model II linear regression (i.e. a reduced major axis regression) was used to estimate the allometric slope (equal to the slope of the regression line). Following Zar (1968) a model II linear regression was used rather than standard ordinary least squares regression because both the $x$ and the $y$-variables are measured with error (Ricker, 1973; Ebert \& Russell, 1994). Next, the parasitic individuals were removed from those species with alternative morphs and the scaling exponents recalculated. A $t$-test was used to compare the scaling exponents from the two regressions, allowing if alternative morphs had any effect on the cross-species allometry to be determined. Lastly, one sample $t$-tests were used to compare the scaling coefficient from the analysis with all males pooled to the 0.904 scaling exponent calculated from Stockley et al. (1997) and to a scaling exponent of 1.0 (isometric growth).

\section{ALLOMETRY WITHIN SPECIES}

For each species, a model II linear regression was performed between gonad and body masses $\left(\log _{10}\right.$ transformed). For species with alternative morphs, all individuals were pooled, and bourgeois and parasitic males were also examined separately. Next, the analysis was repeated using soma mass instead of body mass. Soma mass was calculated from body mass minus gonad mass, and may be more appropriate than body mass in allometry analysis, particularly when the gonads represent a significant proportion of the total body mass (Tomkins \& Simmons, 2002).

Paired $t$-tests were performed on the two sets of scaling exponents (one from the regression using body mass and the other from the regression using soma mass) using: (1) all species and all morphs pooled together, (2) only bourgeois morphs and (3) only parasitic morphs. Next, one sample $t$-tests were used to compare the scaling exponents from the regressions using body mass to the scaling exponent calculated from the cross species analysis, $\alpha=0.904$ calculated from Stockley et al. (1997) and isometric growth $\alpha=1 \cdot 0$. These latter analyses were performed to determine if the average scaling 
exponent calculated within species was equivalent to the exponents calculated from cross species analyses or an ismoetric relationship.

\section{ALLOMETRY ACROSS ALTERNATIVE MORPHS}

For the species with alternative male morphs $(n=6)$, correlation analysis was used to compare the scaling exponents between the parasitic and bourgeois males. Next, a $t$-test was used to compare the scaling exponent of bourgeois males calculated from those species with alternative morphs to the scaling exponents calculated from the remaining species without alterative morphs. This comparison was used to determine if parasitic males affect the allometric relationship in bourgeois males.

All means are reported \pm S.E. and all statistics were performed using SPSS (v. 12.0) or Microsoft Excel (v. Office 2000).

\section{RESULTS}

\section{DATA COLLECTION}

Thirty-seven scientists were contacted, of which 16 responded with data, resulting in gonad and body masses for 23 species encompassing 11 families. For each species, the data were collected during the reproductive season. For 20 of the species, gonad and body masses were obtained for between 13 and 1240 individuals (mean $=221 \pm 70$ ), and for the remaining three species only the coefficients from the gonad and body mass regression analysis were obtained. Six of the species had alternative morphs and 17 of the species had only the bourgeois morph (Table I).

\section{ALLOMETRY ACROSS SPECIES}

A significant positive relationship was found between $\log _{10}$ gonad mass and $\log _{10}$ body mass across all species (alternative morphs were pooled together) with $\alpha=1.04 \pm 0.02\left(r^{2}=0.847, P<0 \cdot 001, n=20\right.$; Fig. 1$)$. Removing the parasitic males from species with alternative morphs had little effect on the estimate of the scaling exponent $\left(\alpha=1.02 \pm 0.02 ; r^{2}=0.847, P<0.001, n=20\right)$ and the scaling exponents did not differ significantly from the two regressions ( $t$-test, d.f. $=36, P=0.45$ ). The scaling exponent of $\alpha=1.04$ observed in the study was significantly different from the scaling exponent of $\alpha=0.904$ calculated from Stockley et al. (1997) ( $t$-test, d.f. $=19, P<0 \cdot 001)$, but was not significantly different from isometric growth $\alpha=1 \cdot 0$ ( $t$-test, d.f. $=19, P=0 \cdot 065)$.

\section{ALLOMETRY WITHIN SPECIES}

For individual species, scaling exponents for the relationship between gonad mass and body mass ranged from 0.68 for Salmo salar L. (parasitic males) to 3.9 for Scianeops ocellatus (L.) (Table I and Fig. 2). Similarly, the scaling exponent between gonad mass and soma mass ranged from $0 \cdot 71$ for Oncorhynchus nerka (Walbaum) to 3.9 for $S$. ocellatus (Table I). When morphs were pooled within species, the scaling exponent was $>1$ showing a positive allometric relationship for $65 \%$ (15 of 23 ) of the species using body mass and 59\% (13 of 22) of the 


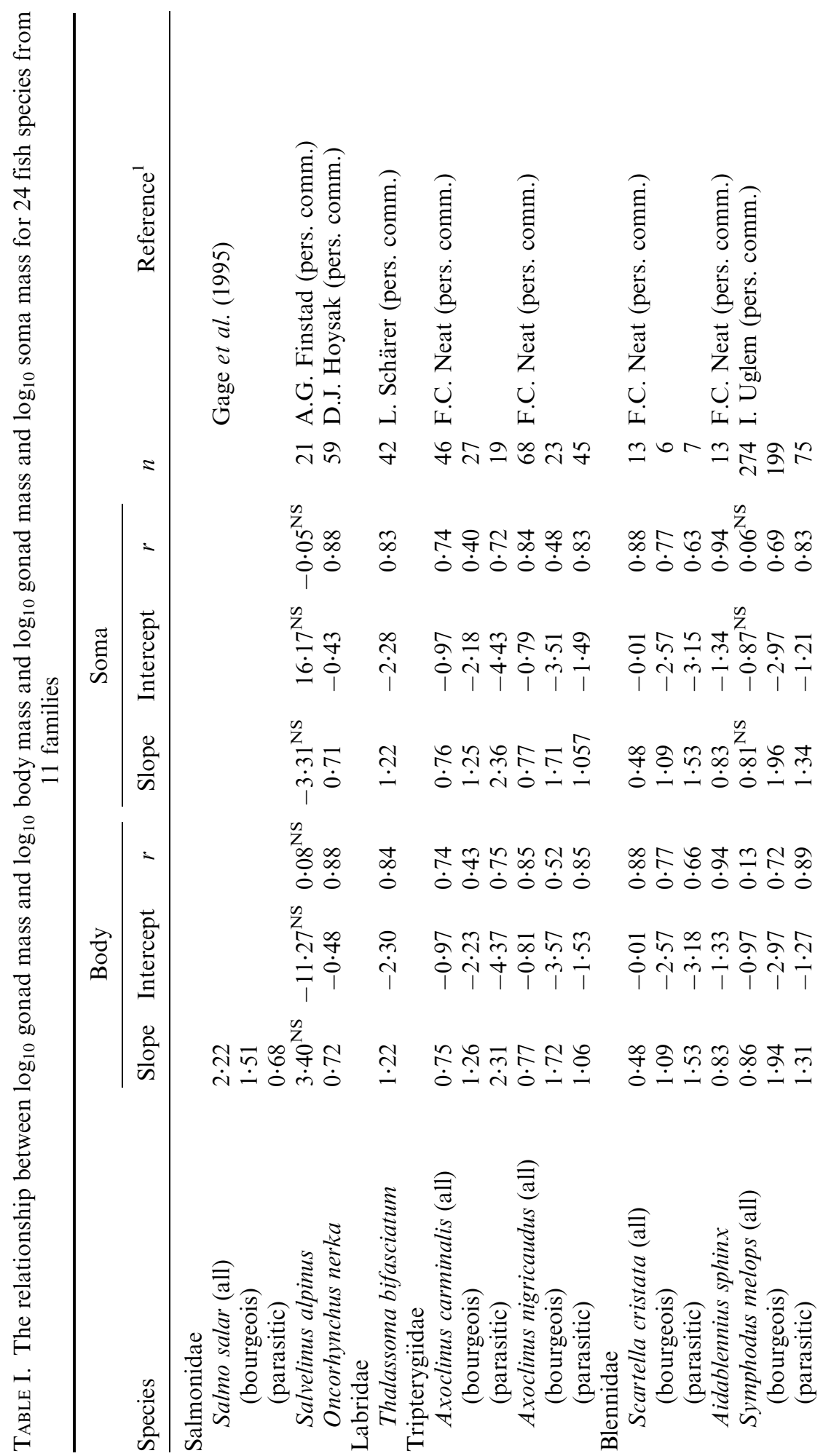




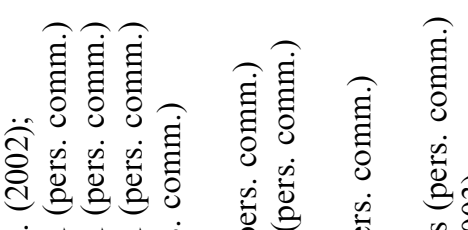

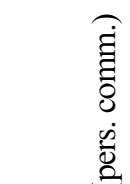

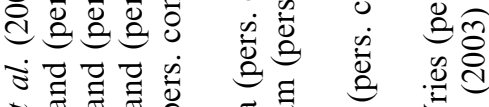

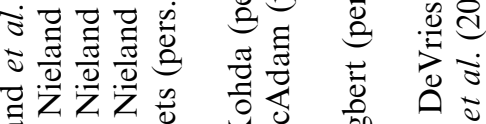

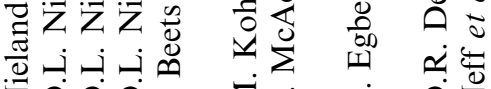

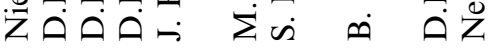

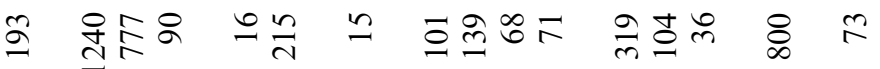

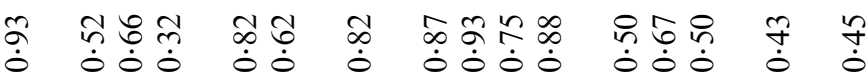

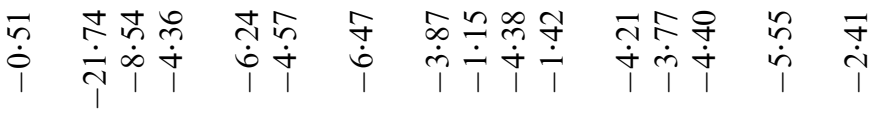

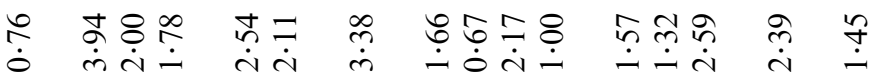

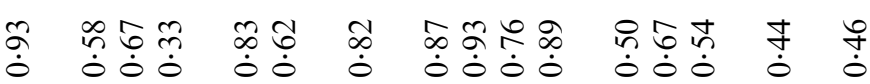

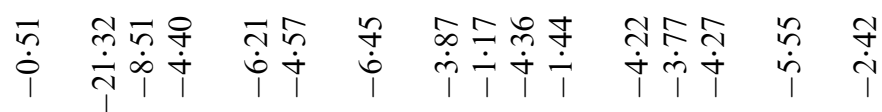

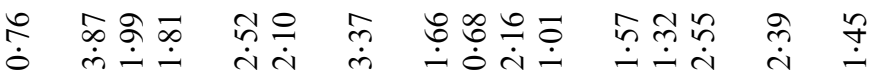

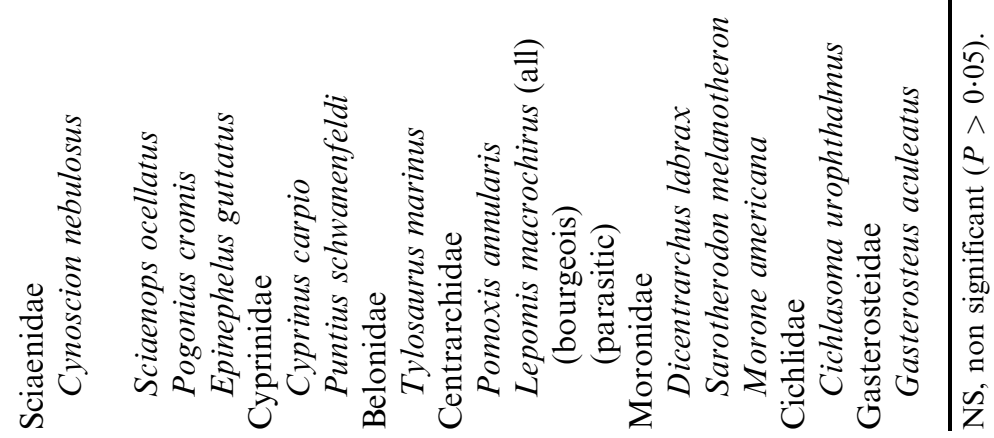




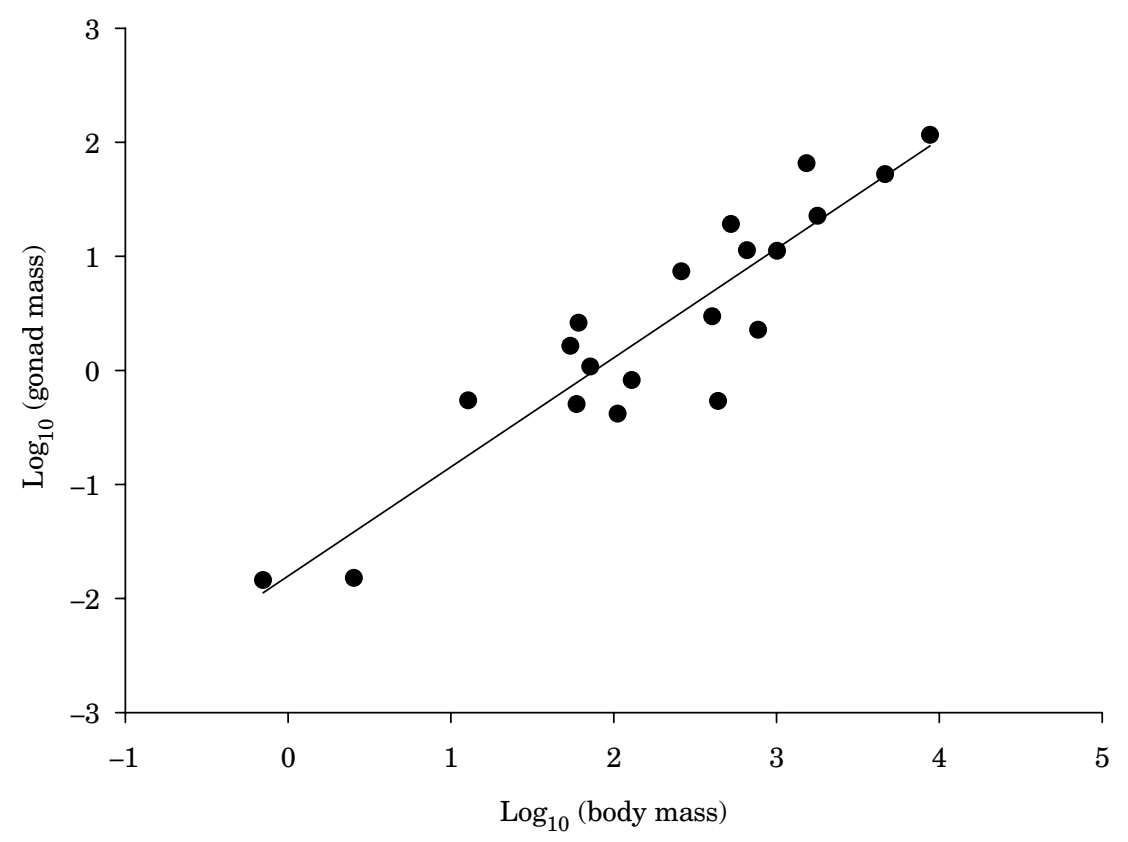

FIG. 1. The relationship between mean gonad mass $\left(\log _{10}\right)$ and mean body mass $\left(\log _{10}\right)$ of 20 fish species. The equation for fitting the curve is: $y=1 \cdot 04 x-1.99$.

species using soma mass. Comparison of scaling exponents from the regressions using body mass and from the regressions using soma mass showed no significant difference when all species were analysed and morphs were pooled (body: $1 \cdot 7 \pm 0 \cdot 2$, soma: $1 \cdot 4 \pm 0 \cdot 3$; $t$-test, d.f. $=21, P=0 \cdot 33$ ), when only the bourgeois morphs were included in the analysis (body: $1 \cdot 9 \pm 0 \cdot 2$, soma: $1 \cdot 6 \pm 0 \cdot 3$; $t$-test, d.f. $=21, P=0.34)$ and when only parasitic morphs were included in the analysis (body: $1 \cdot 4 \pm 0 \cdot 2$, soma: $1 \cdot 4 \pm 0 \cdot 2$; $t$-test, d.f. $=4, P=0 \cdot 33$ ). The scaling exponent of 1.04 calculated from the cross species analysis was significantly different than the mean scaling exponent within species $(1 \cdot 7 \pm 0 \cdot 2 ; t$-test, d.f. $=22, P=0.003)$. The scaling exponent from the within species analysis was also significantly different from the scaling exponent of 0.904 calculated from Stockley et al. (1997) ( $t$-test, d.f. $=22, P<0 \cdot 01)$ as well as a scaling exponent of $1 \cdot 0(t$-test, d.f. $=22, P=0 \cdot 002)$.

\section{ALLOMETRY ACROSS ALTERNATIVE MORPHS}

The scaling exponents calculated for parasitic and bourgeois males were not correlated across species $(r=-0 \cdot 51, P=0 \cdot 30, n=6)$. The scaling exponent of bourgeois males from species with alternative morphs $(\alpha=1 \cdot 6 \pm 0 \cdot 2)$ was not significantly different than the scaling exponent calculated from the bourgeois males from species without alternative morphs $(\alpha=2 \cdot 0 \pm 0 \cdot 2 ; t$-test, d.f. $=21$, $P=0 \cdot 38$; Fig. 2). 


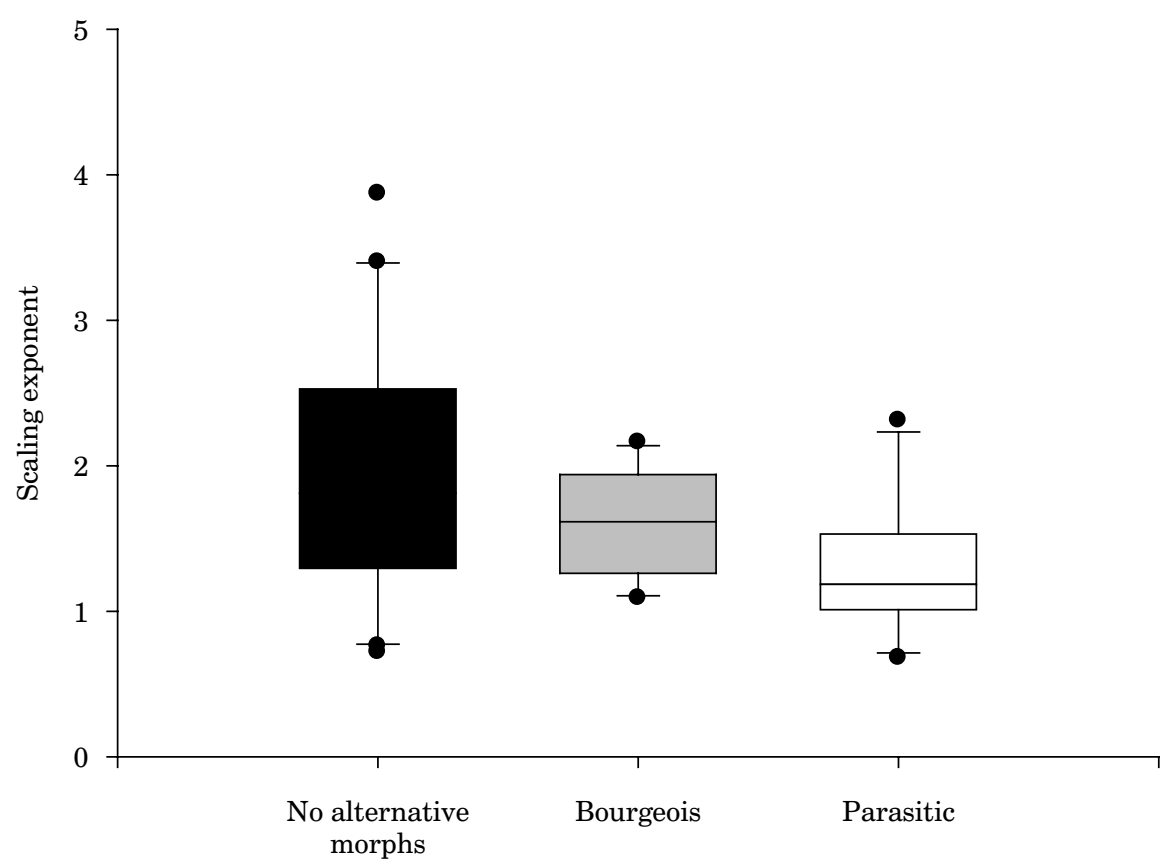

FIG. 2. Box plots summarizing the allometric scaling exponents derived from regressions of gonad mass $\left(\log _{10}\right)$ and body mass $\left(\log _{10}\right)$ for 23 fish species. Plots are broken down into bourgeois males from species without alternative morphs $(\boldsymbol{\square} ; n=17$ species $)$, bourgeois males from species with alternative morphs $(\square ; n=6)$ and parasitic males from species with alternative morphs $(\square ; n=6)$. The lower and upper boundaries of the box denote 25 th and 75 th percentiles, respectively, the line within the box denotes the median, the lower and upper whisker denotes the 10th and 90th percentiles, respectively, and the dots denote outliers. For the no alternative morph category, the outliers are Oncorhynchus nerka (scaling coefficient $=0 \cdot 72)$, Cynoscion nebulosus $(0 \cdot 76)$, Salvelinus alpinus (3.40) and Sciaenops ocellatus (3.87). For the bourgeois category, the outliers are Scartella cristata $(1 \cdot 09)$ and Lepomis macrochirus (2·16). For the parasitic category, the outliers are Salmo salar $(0 \cdot 68)$ and Axoclinus nigricaudus $(2 \cdot 31)$.

\section{DISCUSSION}

Demonstrating an isometric relationship between gonad and body masses is required if comparisons of individuals' $I_{\mathrm{G}}$ are to provide meaningful tests of relative investment into sperm competition. Here, the first study has been undertaken that tests whether or not an allometric relationship between gonad and body masses exists across different fish species, across individuals within a species and across individuals within mating tactics (bourgeois or parasitic).

Across species a scaling exponent of 1.04 was found between gonad and body masses, which was not significantly different from isometric growth (i.e. $\alpha=1$ ). This cross species scaling exponent, however, was significantly different than the value of 0.904 calculated from Stockley et al. (1997). The overlap of fish species used in the two studies was 11 (55\% of the present sample). Thus, differences in the species examined may explain the difference between the results. Furthermore, both analyses may be confounded by phylogenetic nonindependence. Harvey \& Pagel (1991) recommend that linear contrasts be used 
to determine if functional relationships differ based on taxonomic levels (e.g. genera or family).

The present within species analysis suggests that there is not a single allometry between gonad and body masses in fishes. Scaling exponents varied widely across the 23 species analysed $(0 \cdot 68-3 \cdot 9)$ and the average of these exponents was significantly different from the exponent of 0.904 calculated from Stockley et al. (1997), the exponent of 1.04 calculated for the present cross species analysis and the scaling exponent for isometric growth $(\alpha=1)$. Thus, simple comparisons of $I_{\mathrm{G}}$ among individuals within species (e.g. between parasitic and bourgeois males) may not accurately reflect investment into gonads and sperm production (DeVlaming et al., 1982).

As an alternative approach to comparing $I_{\mathrm{G}}$, Tomkins \& Simmons (2002) have suggested that an ANCOVA be used to detect differences in investment into gonads between parasitic and bourgeois males. The ANCOVA can account for species-specific allometries between gonad and body masses, but this approach assumes that there is an equivalent allometry within the parasitic and bourgeois morphs. The present analysis found no correlation between allometries for alternative morphs within species and therefore does not support this assumption (Neff et al., 2003). Tomkins \& Simmons (2002) suggest when allometries differ between morphs that one of the slopes or the pooled slope be used in the covariance adjustment. The biological significance of such adjustments and thus the general utility of the ANCOVA approach, however, remains unclear.

Four additional approaches researchers could use to investigate the relative investment into gonads between alternative morphs and ultimately test Parker's (1990) model of sperm competition are recommended. First, the most straightforward systems to investigate the relative investment into gonads between alternative morphs are those in which the two types of individuals have similar ranges in body size. For example, the European earwig Forficula auricularia males are dimorphic having either large forceps (fighters) or short forceps (sneakers) (Forslund, 2003). Males that adopt the alternative morphs overlap to a large extent in body size. Thus, in earwigs, and similar systems, any underlying allometric relationship between body and gonad masses should have little impact on analysis of gonadal investment. Second, when morphs do not overlap in size but there is no relationship between gonad and body masses (i.e. $\alpha=0$ for both morphs), then a simple comparison of $I_{\mathrm{G}}$ values is appropriate to determine the relative investment into gonads made by alternative morphs. Third, when morphs do not overlap in size and there is a common relationship between gonad and body masses, then the underlying allometric relationship between gonad and body masses must be assessed. When there is a positive allometry and parasitic males are smaller than bourgeois males, comparisons of $I_{\mathrm{G}}$ will provide a conservative test of the relative investment into gonads made by parasitic males and thus a conservative test of Parker's (1990) model. When the allometry is instead negative, comparisons of $I_{\mathrm{G}}$ will provide a biased test of the relative investment into gonads and may provide false evidence for Parker's (1990) model. Fourth, when there is no common allometry between morphs, any difference in $I_{\mathrm{G}}$ between morphs cannot be due to allometric growth. The present analysis suggests this last situation may be common. 
Tomkins \& Simmons (2002) have criticized also the use of body mass in analyses of gonad and body size allometries. They correctly point out that because body mass includes the mass of the gonads, the latter mass is a component of both the dependent and independent variables, which can result in spurious correlations (Zar, 1999). Tomkins \& Simmons instead suggest that soma mass, calculated from body mass minus gonad mass, should be used in allometric studies. In the present analyses of 23 fish species no significant difference was found between the scaling exponents calculated from regressions using body mass $v$. soma mass. Among these fishes, gonad mass represented a small proportion of body mass at $<2 \%(0 \cdot 019 \pm 0 \cdot 016)$. Thus, it appears that the effect of using body mass instead of soma mass is negligible when gonad mass does not represent a significant proportion of the total body mass. Nevertheless, in other classes the proportion of gonad mass to body mass may be considerably higher than the $2 \%$ observed here. For example, in the sharptailed sandpiper Calidris acuminata gonad mass represents $7 \%$ of body mass (T.E. Pitcher, pers. comm.). In principle, soma mass should be used in allometric analyses to avoid spurious correlations.

We are grateful to all the researchers that shared their data. We thank T. Hain and two anonymous reviewers for comments on the manuscript. The work was supported by the Natural Science and Engineering Research Council of Canada and by an Ontario Graduate Scholarship to JAS.

\section{References}

Birkhead, T. R. \& Møller, A. P. (1991). Sperm Competition in Birds: Evolutionary Causes and Consequences. San Diego, CA: Academic Press.

Brody, S. (1945). Bioenergetics and Growth. New York: Reinhold.

DeVlaming, V., Grossman, G. \& Chapman, F. (1982). On the use of the gonosomatic index. Comparative Biochemistry and Physiology 73, 31-39.

Ebert, T. A. \& Russell, M. P. (1994). Allometry and model II non-linear regression. Journal of Theoretical Biology 168, 367-372.

Forslund, P. (2003). An experimental investigation into status-dependent male dimorphism in the European earwig, Forficula auricularia. Animal Behaviour 65, 309-316.

Gage, M. J. G. (1994). Associations between body size, mating pattern, testis size and sperm lengths across butterflies. Proceedings for the Royal Society of London 258, 247-254.

Gage, M. J. G., Stockley, P. \& Parker, G. A. (1995). Effects of alternative male mating strategies on characteristics of sperm production in the Atlantic salmon (Salmo salar): theoretical and empirical investigations. Philosophical Transactions of the Royal Society of London 350, 391-399

Gould, S. J. (1966). Allometry and size in ontogeny and phylogeny. Biological Review 41, $587-640$.

Harcourt, A. H., Harvey, P. H., Larson, S. G. \& Short, R. V. (1981). Testis weight, body weight and breeding system in primates. Nature 293, 55-57.

Harvey, P. H. \& Pagel, M. D. (1991). The Comparative Method in Evolutionary Biology. Oxford: Oxford University Press.

Jennions, M. D. \& Passmore, N. I. (1993). Sperm competition in frogs: testis size and a 'sterile male' experiment on Chiromantis xerampelina (Rhacophoridae). Biological Journal of the Linnean Society 50, 211-220.

Møller, A. P. \& Birkhead, T. R. (1998). Sperm Competition and Sexual Selection. San Diego, CA: Academic Press. 
Møller, A. P. \& Briskie, J. V. (1995). Extra-pair paternity, sperm competition and the evolution of testis size in birds. Behavioural Ecology and Sociobiology 36, 357-365.

Neat, F. C. (2001). Male parasitic spawning in two species of triplefin blenny (Tripterigiidae): contrasts in demography, behaviour and gonadal characteristics. Environmental Biology of Fishes 61, 57-64.

Neff, B. D., Fu, P. \& Gross, M. R. (2003). Sperm investment and alternative mating tactics in bluegill sunfish (Lepomis macrochirus). Behavioral Ecology 14, 634-641.

Nieland, D. L., Thomas, R. G. \& Wilson, C. A. (2002). Age, growth and reproduction of spotted seatrout in Baratatia Bay, Louisiana. Transactions of the American Fisheries Society 131, 245-259.

Parker, G. A. (1970). Sperm competition and its evolutionary consequences in insects. Biological Review 45, 525-567.

Parker, G. A. (1990). Sperm competition games: raffles and roles. Proceedings of the Royal Society of London 242, 120-126.

Ricker, W. E. (1973). Linear regressions in fishery research. Journal of the Fisheries Research Board of Canada 30, 409-434.

Simmons, L. W. (2001). Sperm Competition and its Evolutionary Consequences in Insects. Princeton, NJ: Princeton University Press.

Smith, R. (1984). Sperm Competition and the Evolution of Animal Mating Systems. London: Academic Press.

Stockley, P., Gage, M. J. G., Parker, G. A. \& Møller, A. P. (1997). Sperm competition in fishes: the evolution of testis size and ejaculate characteristics. American Naturalist 149, 933-954.

Taborsky, M. (1998). Sperm competition in fish: 'bourgeois' males and parasitic spawning. Trends in Ecology and Evolution 13, 222-227.

Tomkins, J. L. \& Simmons, L. W. (2002). Measuring relative investment: a case study of testes investment in species with alternative male reproductive tactics. Animal Behaviour 63, 1009-1016.

Zar, J. H. (1968). Calculation and miscalculation of the allometric equation as a model in biological data. BioScience 18, 1118-1120.

Zar, J. H. (1999). Biostatistical Analysis, 4th edn. Upper Saddle River, NJ: Prentice Hill. 